\title{
Mapas Sociales Urbanos, Instrumento de Apropiación del Territorio y Visibilización de Problemas Ambientales
}

\section{Urban Social Maps, Instrument of Appropriation of the Territory and Visibility of Environmental Problems}

\author{
Paula Diez, Miriam Vazquez, Adriana Britos, Sebastian Ruiz \\ pdiez@uarg.unpa.edu.ar,mirian.vazquez@gmail.com,adrisabritos@yahoo.com.ar, \\ geosebaruiz@gmail.com \\ Universidad Nacional de la Patagonia Austral - Unidad Academica Río Gallegos - Piloto \\ Rivero y Av. Gobernador Gregores - Río Gallegos - SantaCruz - Argentina
}

Recibido: 28/05/2020. Aceptado: 14/12/2020

\begin{abstract}
RESUMEN
El trabajo presenta el Proyecto de Extensión "Colegios y Escuelas: un espacio en común para la construcción del conocimiento geográfico" que tiene como finalidad utilizar como estrategia didáctica la construcción del saber disciplinar a partir de la elaboración de cartografía. Los mapas persiguen un trabajo reflexivo de recopilación y tratamiento de información geográfica que permiten, la representación e interpelación del territorio actual y emiten un mensaje que provoca en el estudiante una serie de interrogantes que guían su aprendizaje. En este contex to la extensión universitaria consolida la democratización del saber y favorece la construcción de ciudadanía responsable del territorio que habita.
\end{abstract}

Palabras clave: Cartografía Social; Territorio; Educación; Problemática Ambiental.

\begin{abstract}
The Extension Project "Colleges and Schools: a common space for the construction of geographic knowledge" which aims to use as a didactic strategy the construction of disciplinary knowledge from the elaboration of cartography. The maps pursue a reflexive work of compilation and treatment of geographic information that allow the representation and interpellation of the current territory and emit a message that provokes in the student a series of questions that guide their learning. In this context, university extension consolidates the democratization of knowledge and favors the construction of responsible citizenship of the territory it inhabits.
\end{abstract}

Keywords: Social Cartography; Territory; Education; Environmental Problems.

\section{INTRODUCCIÓN}

El trabajo expone los primeros avances del proyecto de Investigación Cartografía Social: una herramienta para la gestión de los anegamientos urbanos, llevados adelante por docentes e investigadores de la carrera Profesorado en Geografía y Licenciatura en Trabajo Social de la UARG-UNPA y que otorga el marco al Proyecto de Extensión "Actividades de Vinculación 
Universidad - Colegios y Escuelas: Un espacio en común para la construcción del conocimiento geográfico".

La experiencia didáctica se basó inicialmente en el uso de las geotecnologías aplicadas a un estudio de caso que constituye el punto de partida para el desarrollo de diversas actividades relacionadas al uso de imágenes digitales, satelitales, fotografías aéreas, entre otras. De esa forma, además de la recopilación de datos estadísticos de cantidad e intensidad de lluvia, descripción geomorfológica y escurrimiento superficial, se llega a la elaboración de mapas técnicos de superficies anegables y a la detección de los sectores más vulnerables frente a tormentas intensas. Sin embargo, se deja afuera los saberes y experiencias de la comunidad. Es por ello que, en un segundo momento, se seleccionó como método de trabajo el utilizado por la cartografía social ya que promueve procesos de conocimiento y reconocimiento del entorno físico-espacial.

Se consideró necesario lograr un mapa social que exprese la configuración espacial de los anegamientos y permita analizar las causas y consecuencias sobre la problemática que impide el desarrollo de actividades cotidianas, entendiendo que la representación cartográfica posibilita reflexionar acerca del espacio que se habita, del tiempo en que se vive, del entorno cultural y natural. Asimismo, conocer y darle valor a los fenómenos naturales como variables condicionantes del crecimiento y de la configuración de morfología urbana. Pero, sobre todo contenido geográfico, utilizar al mapa como discurso espacial que brinda una imagen política del territorio, cargado de significados culturales y sumido en las tramas del conocimiento / poder (Harley, 1988).

La población seleccionada para la construcción de cartografía social son alumnos del Colegio Secundario $\mathrm{N}^{\circ} 10$ "Gobernador Juan Manuel Gregores", con edades comprendidas entre 16 y 17 años, de la asignatura geografía y que trabajan temáticas de geografía ambiental. El uso de mapas, como lenguaje de comunicación en la geografía escolar, intenta promover que los estudiantes plasmen en el papel los problemas, limitaciones y potencialidades del territorio. El contenido curricular trabajado por los estudiantes de tercer año pertenecientes al ciclo orientado del colegio secundario $\mathrm{N}^{\circ} 10$, se encuentra en el Diseño Provincial de Geografía en el eje "sociedad, ambiente y desarrollo sustentable" el cual expresa "Comprensión de los problemas ambientales regionales y locales, urbanos y rurales; desde diferentes dimensiones, atendiendo a los intereses y al accionar de los distintos actores sociales".

\section{MARCO HISTÓRICO}

\section{Características de la ciudad en la que trabajamos}

La ciudad de Río Gallegos $\left(51^{\circ} 37^{\prime} 27^{\prime \prime} \mathrm{S}\right.$ y $\left.69^{\circ} 12^{\prime} 59^{\prime \prime} \mathrm{O}\right)$ está caracterizada climáticamente por la semiaridez y simbolizada por los vientos predominantes del oeste. Sin embargo, los registros de precipitaciones de fuerte intensidad ocurridos en los últimos años, redireccionó la representación de los habitantes frente a la amenaza que puede provocar un fenómeno climático adverso.

La ciudad presenta diferentes problemas ambientales relacionados con la extensión de la mancha urbana de manera no planificada e incontrolada afectando al medio natural, ejerciendo presión sobre las planicies de inundación, interviniendo sobre los sistemas de drenaje natural mediante el aumento de las superficies pavimentadas y de edificaciones que 
llevan a la acentuación del escurrimiento superficial y una disminución de la infiltración, concentrándose el agua en calles y avenidas (Vazquez et al., 2016). En este contexto y ante el primer indicio de precipitación la población activa las redes sociales generando alertas que tienden sobre todo a impedir la circulación por las calles topográficamente deprimidas y en donde el tránsito provoca oleaje que rompe sobre las edificaciones.

El proyecto de extensión "Colegios y Escuelas: Un espacio en común para la construcción del conocimiento geográfico", pretende la cooperación interactiva entre los docentes y alumnos universitarios con los alumnos y docentes de la escuela media. Además, se trabaja para la construcción de ciudadanía a partir de la responsabilidad social universitaria, en las que se conjugan nuevas estrategias pedagógicas, como la conformación de comunidades de aprendizaje, aprendizaje basado en problemas y proyectos sociales y, revisa la estructura curricular respecto de los problemas de la agenda de desarrollo local y global (Gasca-Pliego y Olvera García, 2011).

La función de la extensión universitaria, según Cedeño Ferrín y Machado Ramírez (2012) consolida la democratización del saber y asume la función social de contribuir a la mayor y mejor calidad de vida de la sociedad desde el conjunto de actividades que identifican los problemas y demandas de la sociedad y su medio, que coordinan las acciones necesarias a partir de esos diagnósticos, y que reorientan y recrean actividades de docencia e investigación a partir de la interacción con ese contexto. En la Universidad Nacional de la Patagonia Austral (UNPA, 2010), la extensión se define como políticas y acciones tendientes a la inserción de la universidad en la sociedad para favorecer el desarrollo económico, político, social y cultural de los diversos sectores de la región propiciando el mejoramiento de la calidad de vida de sus habitantes, en un marco de respeto a los derechos humanos y la protección y cuidado del ambiente".

\section{MARCO TEÓRICO}

\section{Cartografía social instrumento de apropiación del territorio y visibilización de situaciones vulnerables}

El poder de la cartografía se centra en su importancia como herramienta de planificación y de gestión de gobierno. El mapa se presenta como modelo e instrumento, absolutamente no privado de presupuestos ideológicos - como cualquier otra forma de comunicación simbólica -para encarar problemáticas sociales y ambientales (Torricelli G .P., 2000).

Especialmente la cartografía social constituye, desde la conversación, un ritual de intercambio de razones, emociones y experiencias, para producir una nueva visión de la realidad que supera los mitos sobre el progreso, el desarrollo, la razón, el dinero; afianza el sentimiento de la pertenencia a la tierra viviente (Restrepo y Velasco,1998). Los mapas elaborados con cartografía social son "geo culturalmente localizados (y reconocen), tanto en términos técnicos como políticos, la enunciación social del territorio” (Montoya, 2007).

Sin dudas que los mapas no actúan de manera neutra en el espacio, sino que su producción se inscribe en condiciones histórica-sociales válidas para un momento dado. Es decir que su construcción responderá a determinados intereses que reflejarán el carácter políticoideológico. En este particular Leañez (1993) señala la necesidad que existe de comprender el mapa desde una dimensión social, que permita reflexionar acerca de la relación de las 
estructuras y formas espaciales, para lo cual propone la utilización de un cuerpo de conceptos de la teoría del espacio que permitan explicar la dinámica del mismo.

Los mapas materializan en las representaciones nuestros deseos, rediseñan nuestra percepción, definiendo límites, arrastrando identificaciones y fundamentalmente orientando políticas en una u otra dirección. Dennis Wood (1992), en El poder de los mapas, y más recientemente Mark Monmonier, en Como mentir con mapas (1996), mostraron con contundencia que la visión ingenua que reduce los mapas a pictografías y representaciones lo más científicas posibles y en realidad no hace más que esconder el carácter político de cualquier representación. El autor Brian Harley en Maps Knowledge and Power (1988) llama la atención sobre la dimensión sociopolítica del mapa y argumenta sobre la necesidad de producir un cambio epistemológico en la forma de interpretar la naturaleza de la cartografía. Hace énfasis en destacar lo que él llama el aspecto humanístico de los mapas, las circunstancias de su producción y recepción y sus funciones como imágenes del poder. La cartografía dibuja mapas resignificando y rearticulando las fuerzas y potencias que recorren un territorio, preguntándose por las pasiones, los afectos, los humores, las patologías, las fantasías, los relatos, los devenires de las figuras sociales (Duschatzky y Corea 2005).

El fin es construir una imagen del territorio "ciudad de Río Gallegos", definido como el punto de contacto entre espacio y lugar. Lugar como una configuración instantánea de posiciones y al espacio como un cruzamiento de movilidades transitado. Territorio atravesado por el tiempo, que le otorga dinamismo, con implicancias históricas y sociales que construyen, nos construyen y reconstruyen; de límites imprecisos, variables que dependen de las formas del discurso y de relatos individuales y colectivos cargados de historia (Carballeda, 2015). La imagen mental de cada experiencia, saber individual y colectivo es plasmable en mapas sociales que intentan visibilizar y atender los sectores más vulnerables frente a un evento climático adverso.

En la presentación del tema a estudiar inicialmente se utilizaron geotecnologías, que constituyen una nueva forma de acceder y conceptuar la realidad a partir de la aplicación de la informática, tecnologías y conocimientos nuevos con el fin último de tomar decisiones en el territorio (Busai, 2011). Son herramientas, métodos y técnicas que conforman un conjunto de tecnologías destinadas a la obtención, análisis y disponibilidad de información con referencia geográfica (Chuvieco et al, 2005). En un segundo momento, se construyeron mapas sociales, que consideramos permiten, por un lado la apropiación, construcción y descontruccción del territorio; pero sobre todo requiere de aprender a dialogar e intercambiar y respetar opiniones sobre un espacio particular, con el fin de generar una imagen colectiva que deje visibilizado de manera simbólica las vulnerabilidades de diferentes colectivos sociales (Diez Tetamanti, 2018).

\section{RESULTADOS}

\section{Proyecto de Investigación Escolar: Anegamientos en la ciudad una problemática ambiental reciente}

La ciudad se implanta aproximadamente a 15 m.s.n.m, en el estuario del río Gallegos (Fig. 1) con márgenes asimétricos, con una margen norte acantilada y paisaje de meseta y la margen sur baja, modelada por procesos fluvioglaciales. La región presenta un clima templado frío semiárido de meseta y se caracteriza por vientos predominantes del sector oeste-sudoeste y 
una velocidad promedio de $35 \mathrm{~km} / \mathrm{h}$ con ráfagas que alcanzan los $100 \mathrm{~km} / \mathrm{h}$ entre los meses de octubre y marzo y precipitaciones medias que no superan los $240 \mathrm{~mm}$ anuales (Diez, 2017, Soto y Vazquez 2000). El paisaje resultante de este tipo climático se corresponde con vegetación achaparrada xérica, aparentemente de baja biodiversidad.

El análisis del histograma de precipitaciones (Fig. 2) permite visualizar rápidamente que aquellos años que superan la media de $247 \mathrm{~mm}$ corresponden a años húmedos $(2002,417 \mathrm{~mm}$; 2003, $375 \mathrm{~mm}$ y 1976, $365 \mathrm{~mm}$ ); y los años secos son aquellos que quedan por debajo de la media (1993, $163 \mathrm{~mm}$; 1992, $181 \mathrm{~mm}$ y 1974, $188 \mathrm{~mm}$ ). El período 1970-2014 muestra un predominio de años húmedos. Del total de datos analizados, casi el $80 \%$ presenta un comportamiento normal, y el resto corresponde a variaciones que superaron un desvío siempre en sentido positivo.

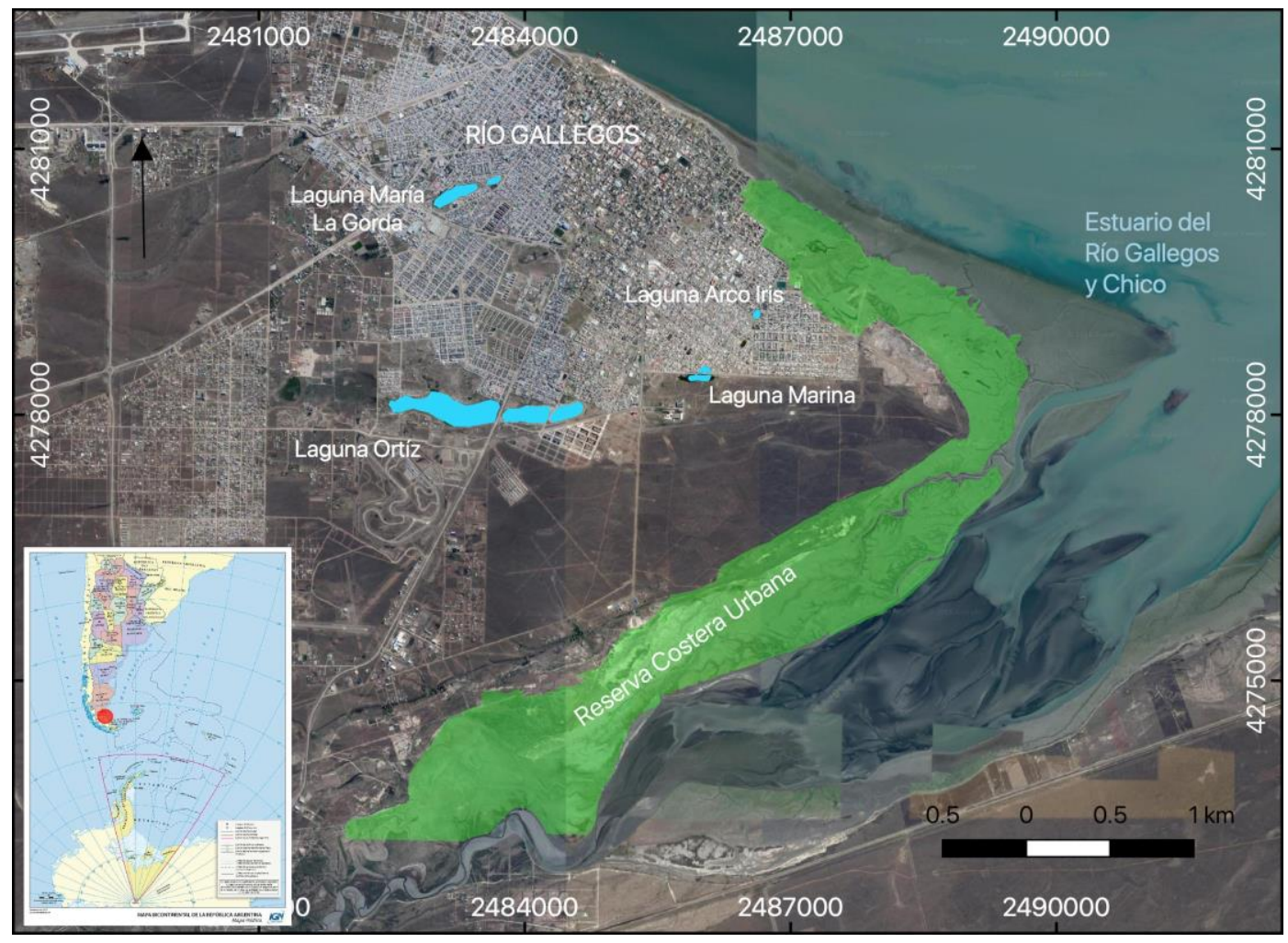

Fig. 1. Localización de la ciudad de Río Gallegos

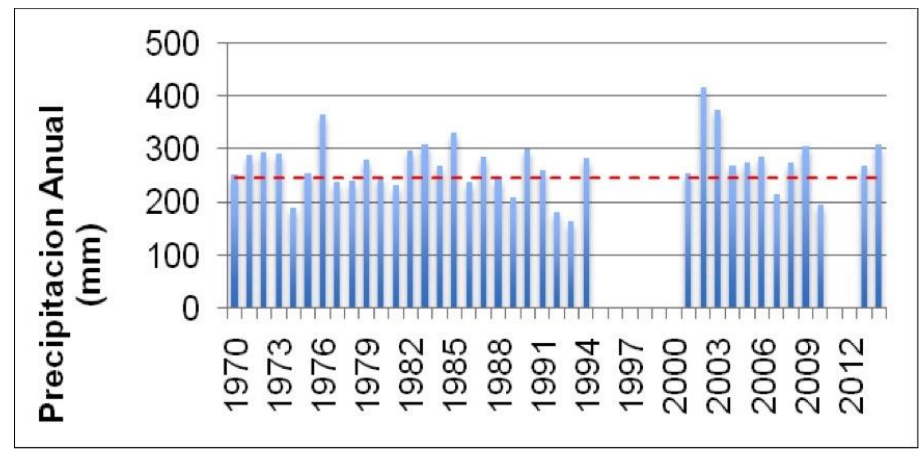

Fig. 2. Hietograma de la Estación Meteorológica Río Gallegos

Fuente: Diez, Paula. (2017). Condiciones climáticas de la ciudad Río Gallegos. Informe Inédito. UARG-UNPA. 
El análisis de fotografías aéreas tomadas en la década del 60 (Fig.3) posibilitaron la lectura y análisis de la geomorfología en la que se implanta la ciudad de Río Gallegos, compuesta por antiguos canales de marea que determinan el sistema hídrico natural, facilitando responder los interrogantes sobre por qué se anega y corroborando que el crecimiento de la mancha urbana obstruyó el escurrimiento natural de agua hacia el estuario.

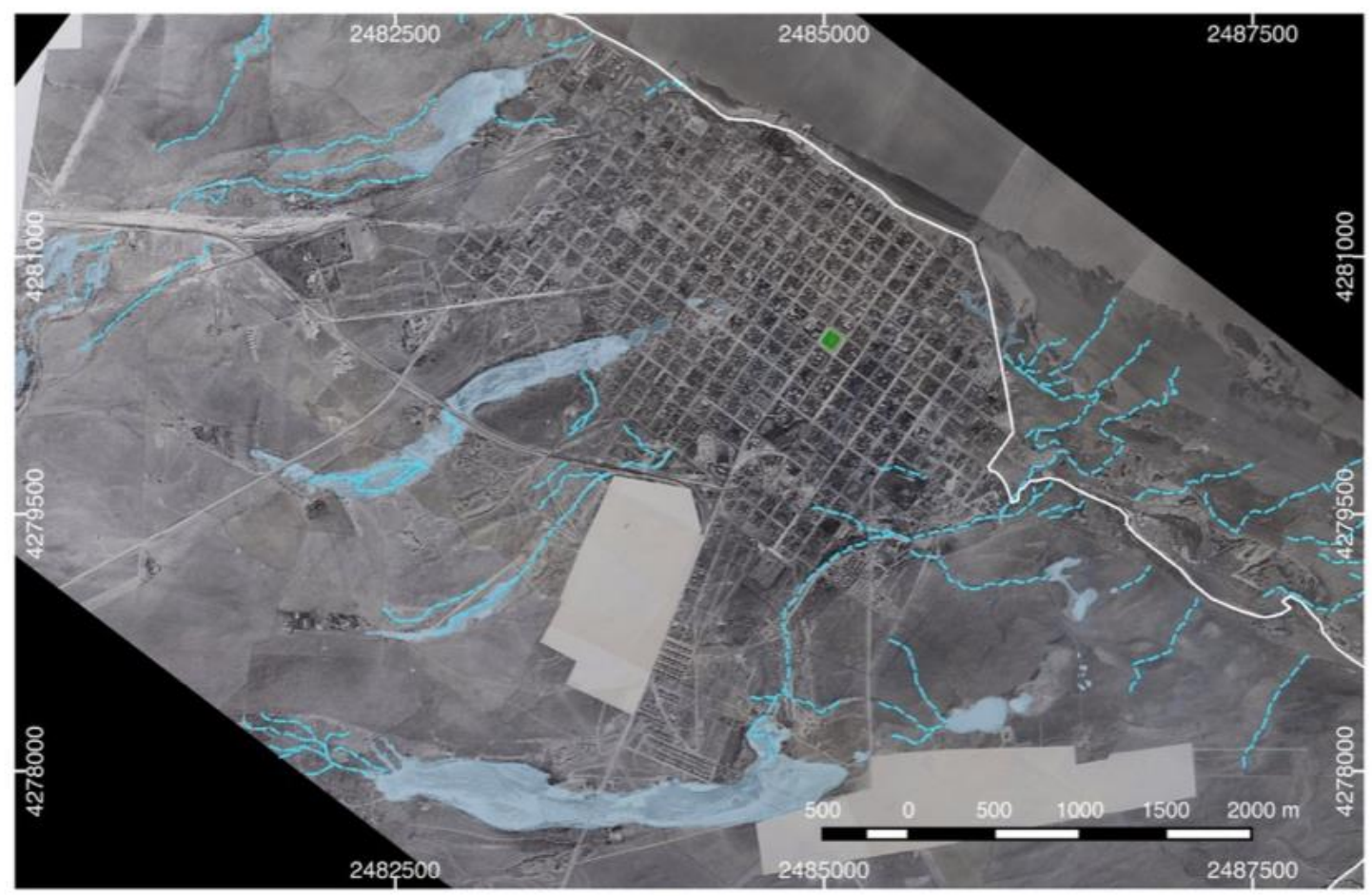

Fig. 3. Mosaico Aerofotográfico de la ciudad de Río Gallegos, año 1965. Se digitalizo la línea de costa en color blanco, el sistema de drenaje natural, los antiguos canales de marea y áreas de lagunas. Se indicó el verde la Plaza San Martín.

La actividad de cierre se centró en la búsqueda de respuestas relacionadas con el relieve en el que se implanta la ciudad. Las fotografías aéreas tomadas en la década del 60` sobre la ciudad de Río Gallegos posibilitaron la lectura y análisis del problema ambiental, facilitando responder los interrogantes sobre por qué se anega, que forma adquieren los anegamientos, si se concentran en un sector o se distribuye dentro de todo el ejido urbano y tratando de establecer semejanzas con el plano actual. Los docentes guiaron la lectura, interpretación y digitalización de la fotografía indicando observar la dimensión y forma de las lagunas, marisma, la línea costa y el sistema hídrico natural relacionado a antiguos canales de marea, se establecieron diferencias con la forma y tamaño de la mancha urbana actual. Con el fin de exponer las diferencias se les presentó una tabla de la pérdida de superficie de lagunas. La pérdida de superficie en las tres lagunas alcanza un total de 61,5 ha (Tabla 1) calculada a partir de las diferencias entre el mosaico aerofotográfico del año 1968 y la imagen satelital de alta resolución del año 2013 y 35, 2 ha de canales de marea de los cuales no quedan evidencias en la morfología actual. También se pudo observar que las lagunas se encuentran fragmentadas y geometrizadas por vías de circulación que alteran el flujo de desagüe natural con el consecuente desecamiento del sector más bajo y la inundación de las calles aledañas (Diez et al 2015). 
Tabla 1. Diferencias en la superficie de cada laguna. Fuente: Diez, et al., (2015)

\begin{tabular}{|l|l|l|l|}
\hline Laguna & $\begin{array}{l}\text { Superficie } \\
1968(\mathrm{ha})\end{array}$ & $\begin{array}{l}\text { Superficie } \\
2013(\mathrm{ha})\end{array}$ & $\begin{array}{l}\text { Perdida } \\
\text { (ha) }\end{array}$ \\
\hline Ortiz & 70 & 40,4 & 29,6 \\
\hline María La Gorda & 35,4 & 5,7 & 29,7 \\
\hline Los Patos & 2,7 & 0,5 & 2,2 \\
\hline \multicolumn{2}{|l|}{ Perdida total de superficie 61,5 } \\
\hline
\end{tabular}

La interpretación de los recursos geotecnológicos y de datos estadísticos concluyó en que el crecimiento urbano no planificado de Río Gallegos y en consecuencia la pérdida del drenaje natural es la causa principal de los anegamientos y que otras variables como falta y/o ampliación de infraestructura, espacios verdes amortiguadores de las precipitaciones y la limpieza de la ciudad contribuyen en la problemática.

Para completar la propuesta de trabajo y poder conocer como ven afectados los alumnos la vida cotidiana se programó un taller que tuvo como objetivo "Conocer como los anegamientos ocurridos en la ciudad de Río Gallegos, durante el 2018, afectan la vida cotidiana".El tema que convoca la realización del taller es incorporar, a la caracterización técnica de la problemática ambiental generada por los anegamientos en la ciudad de Río Gallegos, la dimensión social a partir de las representaciones de los propios actores. Partiendo de este punto se comenzó a pensar como transformar el objetivo en un enunciado corto y sencillo que habilitara el dialogo y la representación en el papel. Se estableció entonces como objetivo cartografiable: "Recordar Río Gallegos cuando llueve", con la finalidad de:

1. Descubrir cuáles son límites de la ciudad para los estudiantes

2. Conocer las actividades que realizan a diario y constituyen su vida cotidiana

3. Localizar los sectores de la ciudad que se inundan

4. Indagar acerca de las estrategias que los distintos actores sociales establecen frente a los anegamientos.

El taller estuvo integrado por el grupo de coordinación, representado por los docentes universitarios integrantes del Proyecto de Extensión, y los cartógrafos sociales, representados por los estudiantes. Las acciones realizadas consistieron en establecer acuerdos con las autoridades del establecimiento educativo para informar sobre el trabajo a realizar; la metodología; posibles días de encuentro con los estudiantes, así como el lugar donde se desarrollaría la actividad.

Se trabajó con los registros de los alumnos a fin de conocer cantidad de estudiantes, edad, lugar de origen y domicilios de los mismos (Fig. 4). Este último dato posibilitaría visualizar y relacionar, la proximidad o no, de los lugares de residencia con la escuela y las zonas anegables, además de analizar la representatividad de la muestra. 


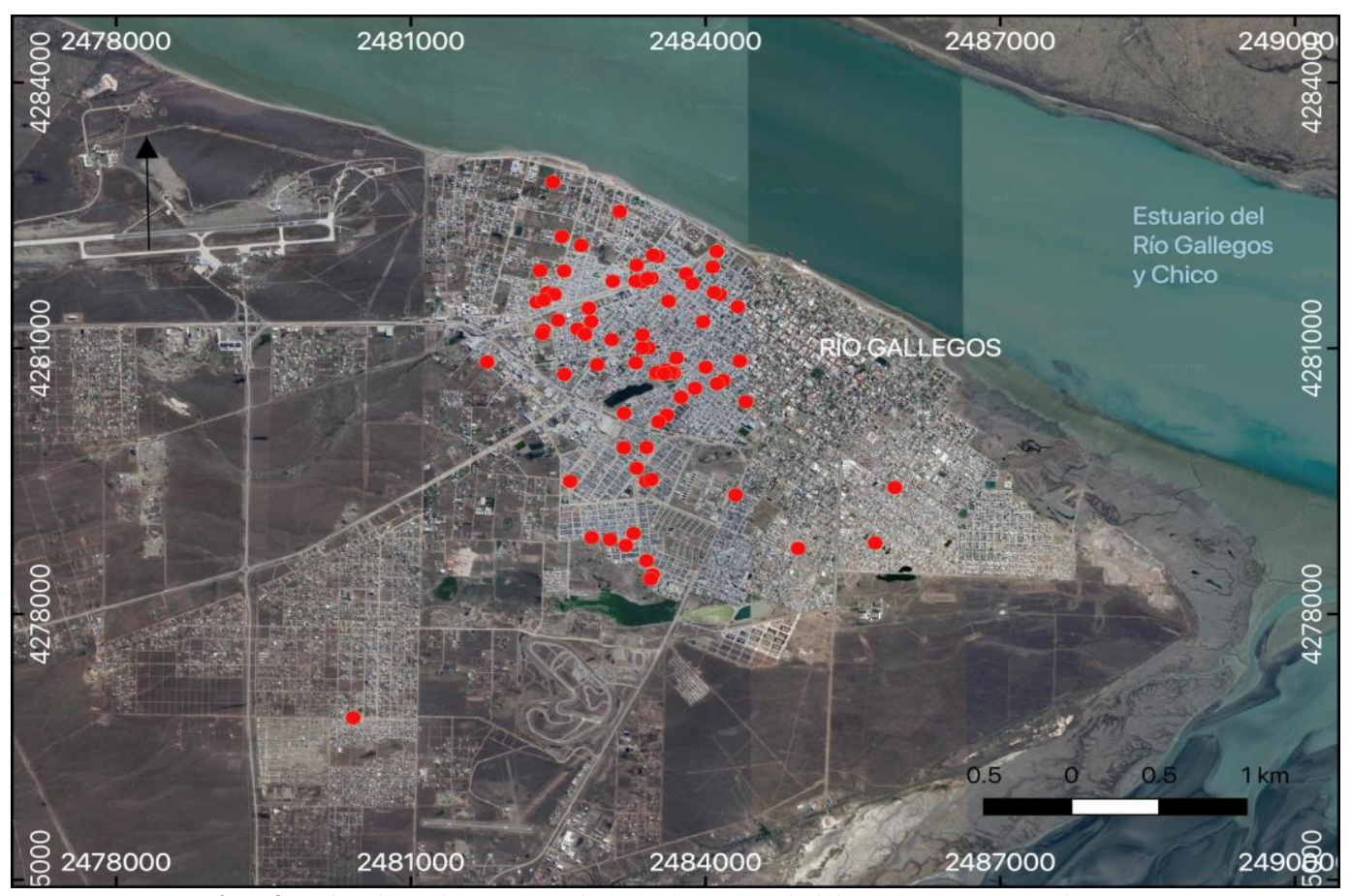

Fig. 4. Distribución espacial de los domicilios de los estudiantes.

La metodología del taller consistió en armar grupos de 5 integrantes, organizados por afinidad. La intención es aprovechar la complicidad de "amigos" para romper con la timidez y/o vergüenza para dibujar. Con el fin de no condicionar el mapa mental, individual y colectivo, se trabajó sobre hojas de papel afiche en blanco (Fig. 5). La Tabla 2, muestra la planificación del taller a partir del objetivo cartografiable:

Tabla 2. Planificación del Taller

\begin{tabular}{|c|c|c|c|c|}
\hline Etapa & Actividad & $\begin{array}{l}\text { Variable } \\
\text { Visual }\end{array}$ & Observaciones & $\begin{array}{l}\text { Tiempo } \\
\text { Estimado }\end{array}$ \\
\hline 1 & $\begin{array}{l}\text { Dibujar Río Gallegos sobre } \\
\text { hoja en blanco. }\end{array}$ & $\begin{array}{l}\text { Color. } \\
\text { Fibrón } \\
\text { negro }\end{array}$ & $\begin{array}{l}\text { Dibujo libre sin } \\
\text { delimitaciones } \\
\text { impuestas }\end{array}$ & 30 minutos \\
\hline 2 & $\begin{array}{l}\text { Representar en el mapa, } \\
\text { dibujado en la Etapa 1, las } \\
\text { actividades que realizan en } \\
\text { su vida cotidiana }\end{array}$ & $\begin{array}{l}\text { Color. } \\
\text { Fibrón } \\
\text { naranja }\end{array}$ & $\begin{array}{l}\text { Se indica incorporar } \\
\text { las actividades } \\
\text { realizadas con } \\
\text { habitualidad de } \\
\text { lunes a domingos }\end{array}$ & 20 minutos \\
\hline 3 & $\begin{array}{l}\text { Dibujar las áreas que } \\
\text { quedan afectadas/anegadas }\end{array}$ & $\begin{array}{l}\text { Color. } \\
\text { Fibrón } \\
\text { celeste }\end{array}$ & & 20 minutos \\
\hline 4 & $\begin{array}{lll}\text { Incorporar como los } & \text { lo } \\
\text { anegamientos } & \text { afecta } & \text { su } \\
\text { vida cotidiana } & & \end{array}$ & $\begin{array}{l}\text { Color. } \\
\text { Fibrón } \\
\text { verde }\end{array}$ & $\begin{array}{lrr}\text { Se indica } & \text { que } & \text { se } \\
\text { puede } & \text { realizar } \\
\text { mediante } & & \text { la } \\
\text { incorporación } & \text { de } \\
\text { texto escrito } & \end{array}$ & 20 minutos \\
\hline 5 & \multicolumn{3}{|c|}{$\begin{array}{l}\text { Se exponen las producciones por grupos, se sociabilizan los } \\
\text { consensos y los conflictos. }\end{array}$} & $\begin{array}{l}\text { No } \\
\text { especificado }\end{array}$ \\
\hline
\end{tabular}




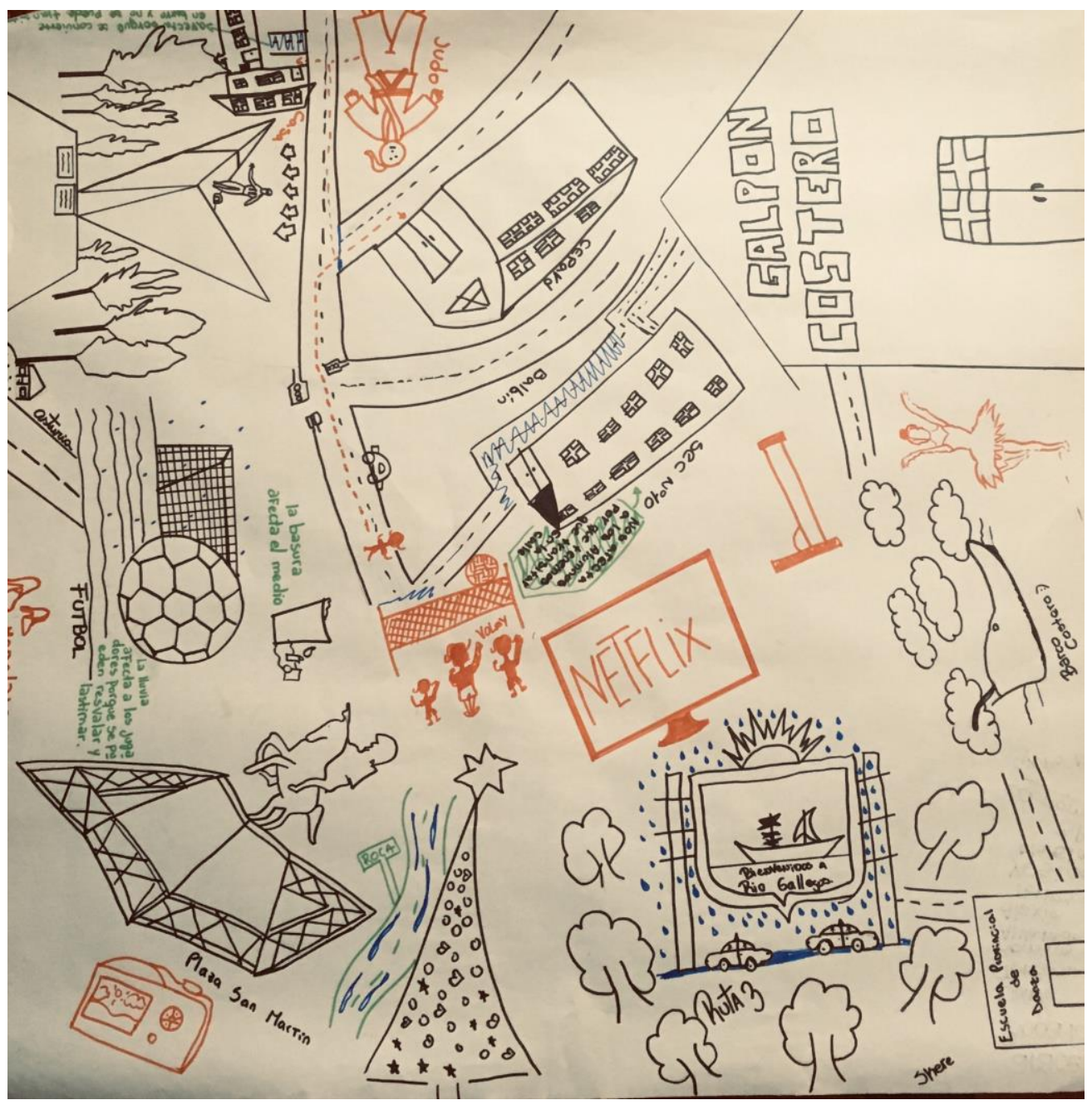

Fig. 5. Mapa social elaborado por el grupo "C"

Las consignas detalladas en la Tabla 2 sobre una hoja en blanco resultaron complejas para lograr la localización espacial de la infraestructura, equipamiento y funciones urbanas. Varios grupos dibujaron el plano "damero", intentando copiar la morfología de la ciudad, no obstante les resultó imposible lograr la generalización de la información para adecuarse al tamaño de la hoja.

En la actividad 1 se solicitaba dibujar los "límites de la ciudad" para definir solo las acciones cotidianas, dicha expresión remitió a los estudiantes a lugares muy alejados de sus recorridos habituales, tanto así que no forman parte del ejido urbano. En algunos mapas se dibujó la frontera Argentino - Chilena "Paso de Integración Austral", que refleja las relaciones familiares y la fuerte conexión comercial entre las localidades de Río Gallegos (Argentina) y Punta Arenas (Chile). Esta última presenta servicios relacionados al esparcimiento, patinaje sobre hielo, zona franca, etc. que constituyen un paseo frecuente entre los habitantes de la localidad.

Respecto de los anegamientos surge que las actividades más afectadas son aquellas gratuitas vinculadas al esparcimiento y recreación en plazas y espacios abiertos de encuentro. También aparece como relevante que el establecimiento educativo tiene serios problemas de accesibilidad en momentos de tormentas, situación que altera el normal desarrollo del dictado de clases. 
En la cartografía técnica quedaron expresadas las calles más anegables y que constituyen vías de circulación que unen distintos barrios (por ejemplo, la intersección de las calles Zapiola y Vélez Sarsfield, Juan José Paso, Presidente Perón, Luis Gotti entre las más afectadas). Estas mismas fueron resaltadas en los mapas sociales como impedimento para el desarrollo de la vida cotidiana. En algunos casos los estudiantes, siguiendo las líneas de las calles, escribieron estrategias frente a la contingencia tales como "no salgo de mi casa", "no voy a la escuela", "tomamos caminos alternativos", "no pasa el colectivo", etc. Entre las cuestiones singulares enunciadas en los mapas se destaca el emplazamiento de un sitio de Internet destinado a la distribución de contenidos audiovisuales (Netflix).

La actividad del taller intentó romper con la cartografía tradicional de lectura e interpretación de datos geográficos y mapas bases (topográficos), posicionando a los estudiantes en el rol activo de cartógrafos sociales. La estrategia didáctica posibilitó abordar contenidos curriculares geográficos físicos y sociales desde una nueva perspectiva utilizando al mapa como instrumento de provocación, dudas e interrogantes. Sin embargo la experiencia generó inquietudes y reclamos sobre la falta de indicaciones que guíen el desarrollo de la actividad.

"...Profe, donde está su conductismo para decirme lo que tengo que hacer..."

Ivana, alumna de 3 "C".

\section{CONCLUSIONES}

El proyecto de extensión "Colegios y Escuelas: Un espacio en común para la construcción del conocimiento geográfico", recupera contenidos curriculares de relevancia social y problemas críticos de la sociedad actual. Estos contenidos permiten entablar diálogo entre la universidad y el colegio secundario $\mathrm{N}^{\circ} 10$, ambas comprometidas en la construcción de ciudadanos responsables del desarrollo económico, político, social y cultural de los diversos sectores de la región, propiciando el mejoramiento de la calidad de vida de sus habitantes, en un marco de respeto a los derechos humanos y la protección y cuidado del ambiente.

En la propuesta de trabajo áulico los mapas presentan un doble rol, por un lado, como instrumento de apropiación del territorio y por otro como lenguaje de comunicación que permite visibilizar las problemáticas ambientales que afectan la vida de los habitantes de la ciudad. La problemática de "Los anegamientos en la ciudad de Río Gallegos", surge de las políticas públicas llevadas a cabo en un medio natural caracterizado por la aridez y que en los últimos años los cambios en las precipitaciones dejaron en evidencia los desatinos de los gestores territoriales y las vulnerabilidades de los habitantes frente al evento climático.

El proyecto de extensión permite afirmar que los estudiantes secundarios están ávidos de pensar, reflexionar y querer mejorar el territorio donde viven. Sin embargo, también sostener que la geografía escolar de la provincia de Santa Cruz tiene mucho camino que recorrer y que existe una gran disociación entre lo descripto en el diseño curricular y propuesto como política educativa con las carencias que acontecen en las escuelas. 


\section{REFERENCIAS}

BUZAI, G. (2011). Geografía y Sistemas de Información Geográfica. Evolución teóricometodológica hacia campos emergentes. Universidad Nacional de Luján. Programa de Estudios Geográficos.

CARBALlEDA, A. (2015). El territorio como relato. Una aproximación conceptual. Ed. Margen $\mathrm{n}^{\circ} 76$.

CEDENO FERRIN, J. y MACHADO RAMÍREZ, E. (2012). Papel de la Extensión Universitaria en la transformación local y el desarrollo social. RevHumMed, vol.12, n.3, pp.371-390. ISSN 1727-8120.

Consejo Provincial de Educación- Diseño Provincial de Geografía.

CHUVIECO, E., BOSQUE, J., PONS, X., CARMELO, C., SANTOS, J. M., GUTIERREZ PUEBla, J., SAlADO, M. J., MARTÍN, M. P., y RIVA J. (2005). ¿Son las Tecnologías de Información Geográfica parte del núcleo de la Geografía? in Boletín de la Asociación de Geógrafos Españoles 40:35-55.

DIEZ, P. (2017). Informe de Impacto Ambiental Construcción de Pluviales en la Ciudad de Río Gallegos. Capítulo Condiciones Climáticas de la Ciudad de Río Gallegos. UARGUNPA. Inédito.

DIEZ, P., VÁZQUEZ, M. y RUIZ, S. (2015). Valoración de los humedales urbanos de la ciudad de Río Gallegos. Contribuciones Científicas GAEA. Sociedad Argentina de $\begin{array}{llll}\text { Estudios } & \text { Geográficos. } & \text { (LATINDEX). } & \text { ISSN }\end{array}$ http://gaea.org.ar/contribuciones/ccgaeaindex.htm.

DIEZ TETAMANTI, J. (2018). Cartografía social. Teoría y método. Estrategias para una eficaz transformación comunitaria. Ed. Biblios (Metodologías). ISBN 978-987-691648-6.

DUSCHATZKY, S. y COREA, C. (2005). Chicos En Banda. Los Caminos de la subjetividad en el declive de las instituciones. Editorial: PAIDÓS Colección Tramas Sociales. ISBN 9789501245158.

GASCA PLIEGO, E., y OLVERA GARCÍA, J. (2011). Construir ciudadanía desde las universidades, responsabilidad social universitaria y desafíos ante el siglo XXI. Convergencia, Revista de Ciencias Sociales. N ${ }^{0} 56$. Universidad Autónoma del Estado de Mexico. Pp37-58. ISSN 1405-1435.

HARLEY, J. B. (1988). Maps, Knowledge and Power. History of Cartography. Chicago and London, University of Chicago Press.

LEAÑEZ, F. (1993). Producción Cartográfica bajo el Enfoque Geohistórico: Una aproximación a la realidad desde algunas comunidades del Amazonas y Puerto Ayacucho. Trabajo de Grado de Maestría. Instituto Pedagógico de Maracay, "Rafael Alberto Escobar Lara".

MONMONIER, M. (1996). How to lie withmaps. Chicago, Illinois. University of Chicago.xiii, 207 p. Edición ; 2 a ed.

MONTOYA ARANGO, V. (2007). El mapa de lo invisible. Silencios y gramática del poder en la cartografía. Universitas humanística no.63, pp: 155-179. Bogotá - Colombia ISSN 0120-4807.

RESTREPO, G. y VELASCO, A. (1998). Cartografía social. Bogotá - Colombia, Publicación del Instituto Geográfico Agustín Codazzi

SOTO, J. y VAZQUEZ M. (2000). Las condiciones climáticas de la provincia de Santa Cruz. El Gran Libro de la Provincia de Santa Cruz. El Gran Libro de la Provincia de Santa Cruz. I, 89-98. Alfa Centro Literario y Milleniun. Madrid, España. 
TORRICELLI, G. P. (2000). El Mapa: Imagen, Modelo e Instrumento Historia, teoría y aplicación en las ciencias sociales y económicas. Materiales del curso de Postgrado. Maestría en Políticas Ambientales y Territoriales (octubre - noviembre 1998). Universidad de Buenos Aires. Buenos Aires. Lugano.

VAZQUEZ, M., DIEZ, P., RUIZ, S. y ASUETA, R. (2016). Percepción Ambiental de una fábrica de ladrillos, Ciudad de Río Gallegos. Actas Científicas Congreso Internacional de Geografía. $77^{\circ}$ Semana de la Geografía. Pag. 267 a 278.

WOOD, D. (1992). The Power of Maps. New York, Guilford Press. 